\title{
A comparison of high-resolution and standard cardiovascular magnetic resonance myocardial perfusion imaging for the detection of myocardial ischaemia
}

Neil Maredia ${ }^{1 *}$, John P Greenwood ${ }^{1}$, Catherine Dickinson², Aleksandra Radjenovic ${ }^{1}$, Stephen G Ball ${ }^{1}$, Sven Plein ${ }^{1}$

From 2011 SCMR/Euro CMR Joint Scientific Sessions

Nice, France. 3-6 February 2011

\section{Objective}

To compare high spatial resolution ( $k-t$ BLAST accelerated) with standard-resolution (SENSE-accelerated) myocardial perfusion CMR imaging for the detection of myocardial ischaemia.

\section{Background}

First pass myocardial perfusion imaging by CMR may permit the detection of myocardial ischaemia with greater accuracy than single photon emission computed tomography (SPECT). Technical developments have led to improvements in myocardial perfusion CMR, particularly through accelerated data acquisition methods. These permit the acquisition of data at higher spatial resolution than conventional CMR techniques, though it is unknown whether this improves diagnostic performance.

\section{Method}

Forty-seven patients with chest pain of potentially cardiac origin underwent two adenosine stress and rest myocardial perfusion studies on separate days. For acquisition of high-resolution data, $k-t$ BLAST with eightfold acceleration and 11 training profiles was used, yielding a mean in-plane spatial resolution of $2.0 \mathrm{x}$ $2.0 \mathrm{~mm}$ and $103 \mathrm{~ms}$ shot duration (1). The standard pulse sequence used twofold SENSE acceleration, yielding a mean $2.7 \times 2.7 \mathrm{~mm}$ in-plane resolution and $136 \mathrm{~ms}$ shot duration. Otherwise the 2 pulse sequences were similar (T1-weighted saturation recovery, three short axis slices

${ }^{1}$ University of Leeds, Leeds, UK

Full list of author information is available at the end of the article acquired). Each patient also underwent conventional SPECT and X-ray coronary angiography studies (2). Investigations were reported by observers blinded to the other test results.

\section{Results}

Dark rim artefact diameter was lower using high-resolution than standard CMR imaging $(1.9$ vs. $3.2 \mathrm{~mm}$, $\mathrm{p}<0.001$ ) but image quality did not differ (median score 3 for both, $\mathrm{p}=0.8$ ). The sensitivity and specificity of high-resolution CMR were $83 \%$ and $91 \%$, standard CMR

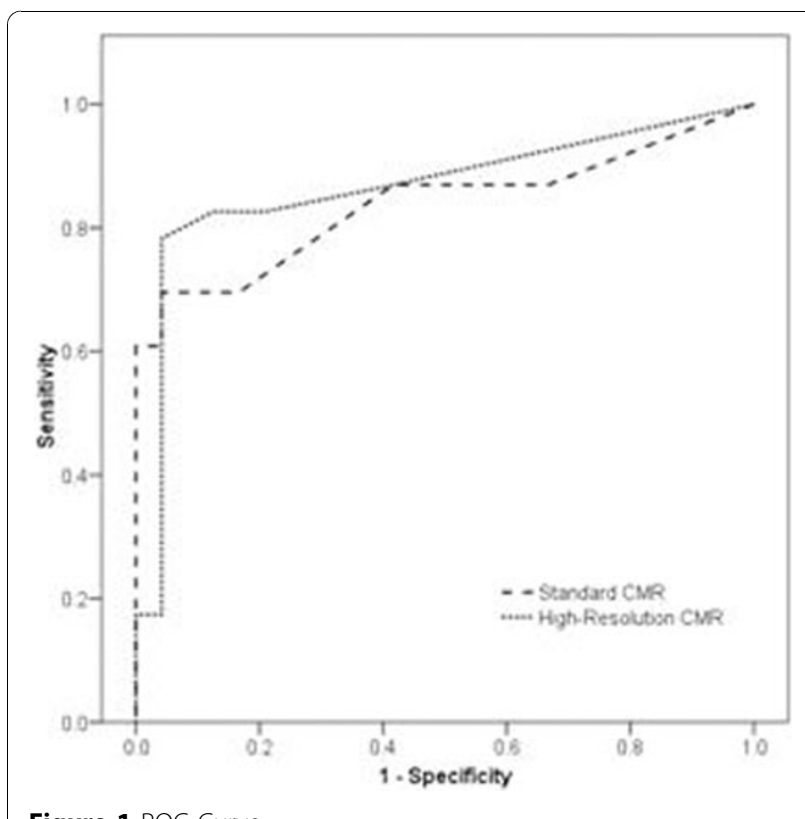

Figure 1 ROC Curve. 


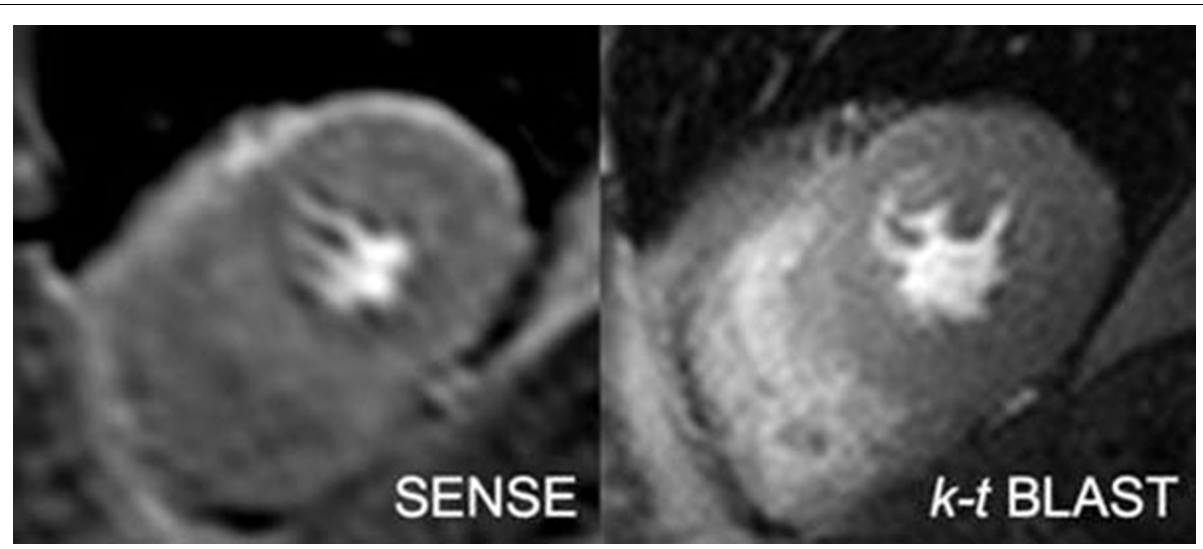

Figure 2 Sample images.

Table 1 Results

\begin{tabular}{lllll}
\hline & $\begin{array}{l}\text { Sensitivity } \\
\mathbf{( 9 5 \% ~ C . I . )}\end{array}$ & $\begin{array}{l}\text { Specificity \% } \\
\mathbf{( 9 5 \% ~ C . I . )}\end{array}$ & $\begin{array}{l}\text { Positive Predictive Value \% } \\
\text { (95\% C.I.) }\end{array}$ & $\begin{array}{l}\text { Negative Predictive Value \% } \\
\text { (95\% C.I.) }\end{array}$ \\
\hline SPECT & $67(43-85)$ & $87(65-97)$ & $82(56-95)$ & $74(53-88)$ \\
Standard SENSE CMR & $74(51-89)$ & $88(67-97)$ & $85(61-96)$ & $78(57-91)$ \\
High-Resolution k-t BLAST CMR & $83(60-94)$ & $91(70-98)$ & $91(68-98)$ & $84(63-95)$ \\
\hline
\end{tabular}

$74 \%$ and $88 \%$, and SPECT $67 \%$ and $87 \%$ but no statistically significant differences were seen. Receiver operator characteristic curve analysis of summed stress perfusion scores revealed similar diagnostic accuracies for highresolution and standard CMR techniques (areas under curve 0.87 and 0.84 respectively, $\mathrm{p}=0.58$; figure 1 ). Respiratory artefacts affected $51 \%$ of high-resolution CMR studies; half of these occurred during the first pass of gadolinium. The presence of respiratory artefact did not have a significant impact on diagnostic accuracy.

\section{Conclusion}

High-resolution and standard CMR myocardial perfusion imaging show similarly high levels of sensitivity and specificity for the detection of X-ray angiography defined coronary artery disease. Both modalities are at least equivalent to SPECT imaging. Larger studies are needed to definitively determine whether diagnostic accuracy is improved with the high-resolution technique.

\section{Author details}

'University of Leeds, Leeds, UK. ${ }^{2}$ Leeds General Infirmary, Leeds, UK.

Published: 2 February 2011

\section{References}

1. Radjenovic, et al: J Cardiovasc Magn Reson 2007, 9(2):213-214.

2. Greenwood, et al: Trials 2009, 10:62.
doi:10.1186/1532-429X-13-S1-P82

Cite this article as: Maredia et al:: A comparison of high-resolution and standard cardiovascular magnetic resonance myocardial perfusion imaging for the detection of myocardial ischaemia. Journal of Cardiovascular Magnetic Resonance 2011 13(Suppl 1):P82.

\section{Submit your next manuscript to BioMed Central} and take full advantage of:

- Convenient online submission

- Thorough peer review

- No space constraints or color figure charges

- Immediate publication on acceptance

- Inclusion in PubMed, CAS, Scopus and Google Scholar

- Research which is freely available for redistribution
Biomed Central 